\title{
Heródoto I 53 y su transmisión en la literatura griega cristiana
}

\author{
Ángel NARRo SÁNCHEZ ${ }^{1}$ \\ Universitat de València \\ Angel.Narro@uv.es
}

Recibido: 14-11-2012

Aceptado: 20-12-2012

\section{RESUMEN}

El oráculo de Delfos ofrece una respuesta al rey lidio Creso que provocará su ataque contra los persas y su propia derrota. Este oráculo que aparece como un hexámetro dactílico por vez primera en la Retórica de Aristóteles llamará la atención de los apologistas cristianos. Pero la transmisión del mismo, a partir de Eusebio de Cesarea,

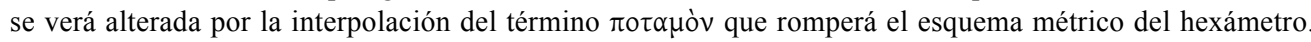
Después podremos distinguir las fuentes de los autores bizantinos que utilizan este oráculo dependiendo de si respetan la forma que nos ofrece Aristóteles o la que aparece en el texto de Eusebio. Así pues, nuestro estudio consistirá en un análisis de la transmisión de dicho oráculo desde la Historia de Heródoto hasta la literatura bizantina, haciendo especial hincapié en la literatura griega cristiana en la que se consolida una segunda variante textual.

Palabras clave: Oráculos, Heródoto, crítica textual, literatura griega cristiana, tradición clásica

\begin{abstract}
The Delphic oracle offers an answer to the Lydian king Croesus that will cause his attack against the Persians and his own defeat. This oracle appears as a dactylic hexameter in Aristotle's Rhetoric for the first time. Then, it

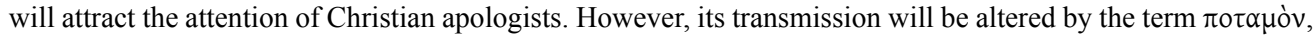
whose addition breaks the metrical scheme of the hexameter. Finally, we will be able to distinguish the sources used by the Byzantine authors who insert this oracle depending on whether they respect the hexameter following Aristotle or they insert the text following Eusebius. Thus, our study aims to analyze the transmission of this oracle from Herodotus' History to Byzantine literature, with particular emphasis on Christian Greek literature, in which this second textual version will be consolidated.
\end{abstract}

Keywords: Oracles, Herodotus, Textual Criticism, Christian Greek Literature, Classical Tradition

\section{SUMARIO}

1. Introducción, 2. Hdt. I 53 en la Retórica de Aristóteles, 3. El oráculo a partir del testimonio de Aristóteles, 4. Una transmisión paralela. Uso de fuentes paganas y cristianas.

${ }^{1}$ Investigador becado por la Conselleria d'Educació de la Generalitat Valenciana gracias al programa de Becas de Formación de Personal Investigador (BFPI). 


\section{INTRODUCCIÓN}

En la Historia de Hérodoto de Halicarnaso encontramos entre los antecedentes de las Guerras Médicas el célebre episodio narrado en el libro primero sobre Creso y su fallido intento por someter el Imperio Persa de Ciro. Todo comienza cuando Creso, rey de los lidios, pueblo que dominaba gran parte de la península de Anatolia por aquel entonces (Hdt. I 6), empieza a desarrollar una fe ciega en los oráculos ofrecidos por el templo de Apolo en Delfos. Tras diversas consultas satisfactorias, éste se convierte en uno de los benefactores principales del templo délfico (Hart 1983: 39-40) y decide formular una pregunta al oráculo que sería crucial y del todo determinante para el devenir de los acontecimientos.

En efecto, Creso quería saber si en el caso de que se decidiera a mover sus tropas contra los persas podría lograr la victoria, embajada que según How y Wells (1928: 75) debemos datar en 555 a.C. y que aparece recogida en la llamada Crónica de Paros (App. XIV 6), aunque otros autores como Cargill (1977: 97-116) prefieren no arriesgarse a aportar una fecha concreta y optan por dar como punto de referencia la mitad del siglo VI. El oráculo contestó que si guerreaba contra ellos destruiría un gran imperio (Hdt. I 53). Enseguida Creso se congratuló al verse como vencedor ante los poderosos persas, aunque desconocía que sucedería justo lo contrario, como señala Manas (2004: 135-137). Lo que ignoraba en realidad era que se trataba de su propio imperio, tomado por las tropas de Ciro como venganza por la invasión de Capadocia, para la cual el ejército lidio había tenido que cruzar el célebre río Halis (hoy en día Kizil Irmak), que separaba los territorios aliados de los persas del propio imperio de Creso (Hdt. I 57).

La respuesta del oráculo, siempre enigmática y ambivalente, era lo que había movido a Creso a acometer tamaña osadía que acabó por costarle el control sobre sus territorios. Sin embargo, la explicación del propio oráculo ante una embajada enviada por el propio Creso era clara y contundente: el único responsable de la derrota frente a los persas había sido el mismísimo rey lidio ya que, cuando el oráculo le anunció que destruiría un gran imperio, dio por supuesto que el damnificado iba a ser el de Ciro sin preguntar a Apolo cuál de los dos sería el que iba a ser derrotado (Hdt. I 90).

En esta parte inicial de la narración en la que se cuenta la historia de Creso, Heródoto aprovecha también para aportar un largo excurso en el que relatará la historia de Lidia y los antepasados del propio rey (Caballero López 2006: 58-59). En ella, cobran una gran relevancia las diferentes consultas oraculares llevadas a término por Creso. Mikalson (2002: 195-196) destaca cómo en la Historia la mayor parte de oráculos suelen predecir correctamente el futuro o bien no han sido interpretados adecuadamente, lo cual se explica, según este autor, por las fuentes utilizadas por Heródoto, las cuales siempre tenderían a recordar los oráculos acertados o a reinterpretar la posible problemática causada en retrospectiva, y por la propia predisposición a la creencia en la veracidad de los oráculos presente en el historiador griego.

La narración de la historia de Creso y su pregunta al oráculo de Delfos gozó de una gran difusión entre los griegos por la importancia de las consecuencias para el posterior conflicto bélico contra los persas y por el hecho de que la opacidad y ambivalencia del oráculo de Apolo hubiera animado el ataque de los lidios al territorio capadocio. A pesar de que en I 91 Heródoto relata cómo el oráculo con gran acierto le respondió lo que 
debería haber preguntado, tratando de dejar incólume la reputación profética del templo délfico, lo cierto es que pronto el pasaje comenzó a interpretarse como una muestra más de la ineficacia de las predicciones de los grandes centros oraculares y como prueba evidente de la falsedad, o al menos de la arbitrariedad, de las profecías dictadas.

Asheri (2011: 114) en su comentario del primer libro de la Historia de Heródoto, considera el pasaje de I 53 como el ejemplo más famoso de la ambigüedad oracular y razón no le falta a tenor de lo que veremos en las siguientes páginas. Así, el objetivo de este estudio no será otro que el de analizar la recepción de dicho oráculo a través de los testimonios directos conservados para acabar centrándonos en la época cristiana en la que el oráculo gozará de una cierta importancia.

\section{HDT. I 53 EN LA RETÓRICA DE ARISTÓTELES}

En efecto, ya desde el siglo IV o quizá antes, la embajada de Creso y la respuesta de Apolo era tema de debate entre los círculos filosóficos. El primero en hacerse eco de la respuesta oracular del dios a Creso es Aristóteles, quién en su Retórica presenta los cinco principios de la correcta expresión entre los cuales incluye el hecho de no emplear palabras ambiguas al estilo de los adivinos, a quienes critica de pasada por no concretar en su expresión, comparando las prácticas oraculares a los juegos de azar (Arist. Rh. 1407a). El aspecto más interesante es que Aristóteles reproduce la respuesta oracular que no se hallaba en Heródoto, quien ofrecía la respuesta en prosa y en estilo indirecto (Crahay 1956: 197-199), de la siguiente manera:

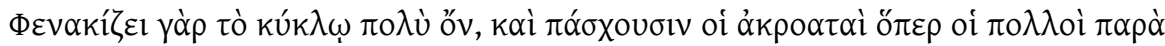

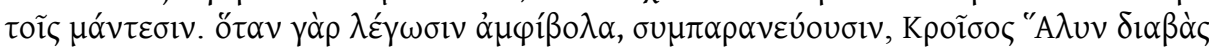

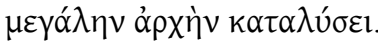

Desde el punto de vista textual el pasaje no presenta problema alguno de lecturas alternativas siguiendo la edición oxoniense de Ross, y respeta las normas del hexámetro a la perfección. La mayoría de los oráculos empleaban el hexámetro por su gran difusión y prestigio, como apuntan West (1982: 35) y Rossi (1981: 204), y quizá por su origen sagrado en relación con la épica y con el estilo formular propio de la épica homérica (Nieto Ibáñez 1998). Además, los oráculos apolíneos muestran una diversidad reseñable de esquemas métricos, si bien parece existir una cierta relación de dependencia con los modelos de Homero y Hesíodo (Nieto Ibáñez 1989).

De vuelta a nuestro oráculo, ya Asheri (2011 : 114) apuntaba cómo habría sido elaborado post eventum, de la misma manera que Fontenrose (1978: 301-302) lo catalogaba directamente de 'not genuine'. Nieto Ibáñez (2011: 123), por su parte, opina que la mención del río Halis es una deducción ex eventu a partir del relato siguiente de Heródoto. En efecto, todos los estudiosos tenían razón pues en verdad el oráculo parece estar reescrito, pero sobre la base de Hdt. I 53 y I 91, ya que en ambos pasajes aparece la

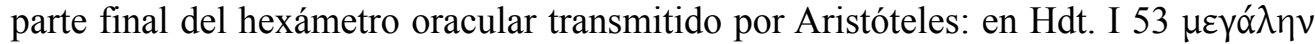

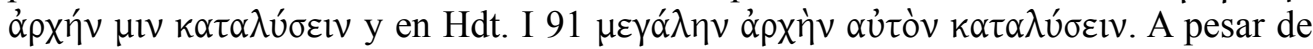


que el pasaje se ha relacionado con el presocrático Empédocles ${ }^{2}$, citado antes de insertar el hexámetro, no parece que Aristóteles aquí le atribuya dichas palabras, las cuales

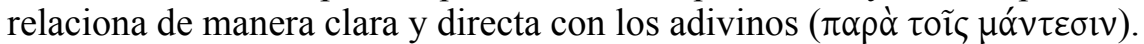

A partir de aquí, la aparición del oráculo en diversos autores griegos se multiplicará de manera exponencial y podremos delimitar dos tipos de autores: aquellos que reproducen directamente el hexámetro recogido por Aristóteles y aquellos que, a partir de Eusebio de Cesarea, el eje central de su transmisión en el cristianismo, utilizan una segunda variante que presenta un problema fundamental desde el punto de vista métrico.

\section{EL ORÁCULO A PARTIR DEL TESTIMONIO DE ARISTÓTELES}

La primera línea de transmisión del oráculo que incluye Aristóteles en su Retórica parece encontrar un punto de inflexión en la Praeparatio evangelica de Eusebio de Cesarea. Hasta el historiador y apologeta cristiano del siglo iv encontramos la respuesta oracular a Creso reproducida de manera literal en la Biblioteca histórica de Diodoro de Sicilia (IX 31, 1), en los Dialexeis (V 2a y XIII 5e) de Máximo de Tiro, e incluso en el segundo libro del De Divinatione de Cicerón (II 115-116), donde traduce al latín el oráculo respetando las exigencias métricas del hexámetro (Croesus Halyn penetrans magnam pervertet opum vim). Además, aparece también en diversos escolios como en los de las Argonáuticas de Apolonio (158, 3), en los del Pluto de Aristófanes (8b 5) o en los de las Troyanas de Sófocles (I 19).

Hasta aquí todo claro. Sin embargo, el problema nace precisamente con Eusebio de Cesarea y su Praeparatio evangelica. Como apunta Nieto Ibáñez (2011: 59-146) en una obra reciente, durante los primeros siglos del cristianismo la atención de buena parte de los apologistas cristianos se concentra en la crítica a los oráculos y en su dudosa capacidad profética. Partiendo del presupuesto de la falsedad de toda profecía divina ajena a los dictados del cristianismo, la política antioracular llevada a cabo por los escritores cristianos sobre todo hasta el siglo $\mathrm{v}$ implica la búsqueda de pruebas fehacientes en los textos antiguos que demuestren la ambigüedad y, mejor aún, el error y la inexactitud de las profecías de los grandes centros oraculares venerados y respetados en la antigüedad griega.

En efecto, uno de los ejemplos más célebres de esta posición condenatoria del profetismo oracular pagano lo encontramos entre los libros IV y VI de la Praeparatio de Eusebio, en la que considera a los oráculos productos de charlatanes y denuncia la ambigüedad de sus palabras (Nieto Ibáñez 2011: 47-52). En dicha obra, el obispo de Cesarea recoge una gran cantidad de respuestas provenientes de diferentes templos de la antigüedad, las cuales suele transcribir de manera literal. De estos oráculos que Eusebio incluye en esta parte de su obra, la mayoría respetan las normas prosódicas del hexámetro sin presentar ninguna alteración significativa. Pero en uno parece haber existido una interpolación añadida que los editores suelen colocar entre corchetes o no

${ }^{2}$ Así lo da a entender Diels (1903: 165) en los testimonios que recoge acerca de los filósofos presocráticos en otros autores. Sin embargo, leyendo el original de Aristóteles, como decimos, se aprecia con claridad que no hace alusión ya a Empédocles, sino a los adivinos. 
incluir directamente como sucede en la Patrología de Migne. Precisamente se trata de este famoso oráculo que recogía la respuesta del dios délfico a la embajada de Creso.

He aquí el problema en cuestión. En la edición clásica de Mras (1952: 260) se recoge el oráculo en $P E \mathrm{~V}$ 21, el mismo que encontrábamos en Aristóteles con una leve alteración, que aun siendo leve, desestabiliza por completo la estructura del hexámetro.

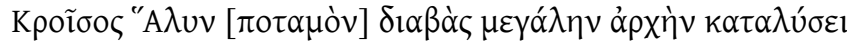

Dicho oráculo aparece también con una crítica similar a la formulada por el obispo de Cesarea en los escritos del cínico Enomao de Gádara, quien recrimina a Apolo la ambigüedad del oráculo y las consecuencias que tuvo (Nieto Ibáñez 2011: 123). Sin embargo, los diferentes autores que se han ocupado de los fragmentos de Enomao no se ponen de acuerdo en si considerar el pasaje como suyo (Vallette 1908: 31-32), o atribuirlo directamente a Eusebio (Hammerstadt 1988).

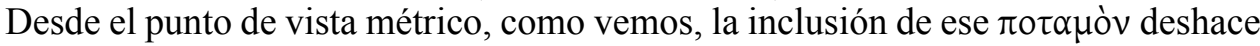
la estructura hexamétrica transmitida por Aristóteles. La formación clásica de Eusebio y el perfecto conocimiento que muestra en sus escritos sobre las prácticas oraculares paganas nos empujan a pensar que éste conocería la forma original del oráculo registrado por Aristóteles y sería consciente de su estructura métrica, por lo que la inclusión

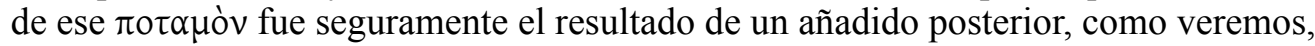
en época bastante temprana.

El porqué de su inclusión es algo que tampoco parece ser demasiado complicado. Según Johnson (2006: 75-77), Eusebio escribe su Praeparatio evangelica en tanto que manual introductorio ( ban las comunidades cristianas de la época. Seguramente, algunos de estos jóvenes desconocían por completo, no ya sólo la ubicación, sino quizá incluso la existencia del propio río Halis, por lo que habría sido necesaria esta pequeña aclaración que ayudara al lector poco avezado. En Estrabón encontramos mencionado el río Halis en cuatro pasajes (Str. XII 2, 8; XII 3, 9; XII 3, 35 y XIV 2, 2), así como en historiadores tardíos como Flavio Arriano (Peripl.M.Eux. XIV 5, 5) o Apiano (Syr. 222, 3; Mithrid. $271,1)$, por lo que parece claro que aún en época cristiana el río Halis seguía conservando su nombre original y todavía no había cambiado. El problema, pues, estaba en los lectores de la Preparatio para cuya mayor comprensión se decidió incluir esta aclaración.

Por otro lado, las consecuencias que tuvo fue la creación de una nueva vía de transmisión, por lo que podremos observar a partir de la Praeparatio de Eusebio dos

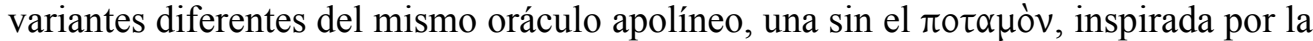
tradición aristotélica, y otra basada en el texto del de Cesarea. Además, la inclusión posterior en los manuscritos de su Praeparatio del término se produjo en una época muy temprana, sin duda entre el siglo iv y finales del v, momento en el que encontramos por primera vez el oráculo recogido respetando la forma alterada que aparecía en la obra de Eusebio de Cesarea. 


\section{UNA TRANSMISIÓN PARALELA. USO DE FUENTES PAGANAS Y CRISTIANAS}

Dejando de lado los testimonios indirectos en los que aparece comentado el caso del oráculo dado a Creso y la nula credibilidad de las respuestas apolíneas, como los de Juan Crisóstomo (Pan.Bab.1 88), Teodoreto de Ciro (Affect. X 26, 3), el Abad Nonno en su comentario sobre los discursos de Gregorio Nacianceno ( $P G 36$, cols. 423-433) y Cosme de Jerusalén en el correspondiente a los poemas también del propio Gregorio ( $P G$ 38, cols. 432-433) (Nieto Ibáñez 2011: 123 n 201), la primera obra en la que encontramos citada la respuesta de Apolo reproducida por Eusebio es la Vida y milagros de Santa Tecla, obra anónima datada entre 444 y 476 (Dagron 1978: 15-19), tradicionalmente atribuida a Basilio de Seleucia (López Salvá 1972; Dagron 1974: 5-6).

En el prólogo de los Milagros es donde se recoge el oráculo de la Praeparatio de Eusebio dentro de una bien articulada crítica a los vaticinios oraculares, a los cuales considera como fábulas, invenciones y fanfarronadas, apuntando directamente a los santuarios de Zeus en Dodona, al de Apolo en Delfos, a las fuentes de Castalia y a los santuarios dedicados a Asclepio en Pérgamo, Epidauro y Egas (Mirac. Thecl. Prol. 29-30). Tras citar literalmente el oráculo, el autor anónimo continúa hablando de las falsas profecías de Apolo y utiliza el término $\Lambda$ o łía s para hacer alusión a éste. La influencia de la Praeparatio evangelica de Eusebio de Cesarea en este pasaje parece bastante evidente: por un lado, encontramos trans-

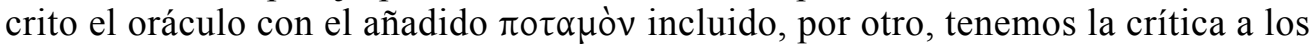
grandes centros oraculares y de curación que aparece en el propio libro quinto de la Praeparatio de Eusebio y, por fin, el adjetivo $\Lambda$ o $\xi$ ía s atribuido a Apolo que aparece también comentado por el obispo de Cesarea en ese mismo libro (PE V 35) (Narro 2010: 132-133).

\footnotetext{
'Ү

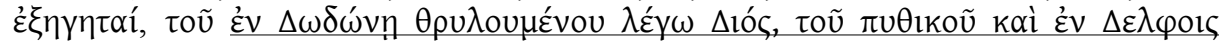

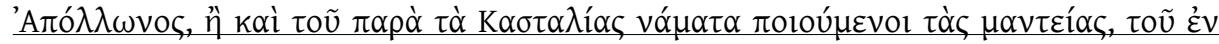

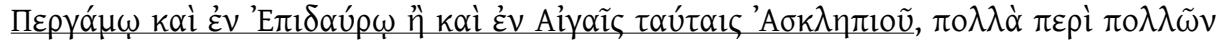

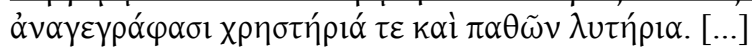

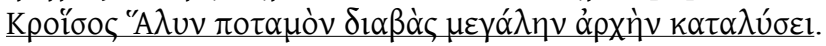

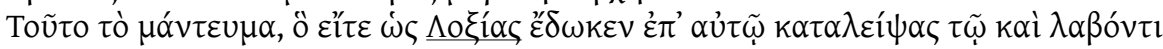

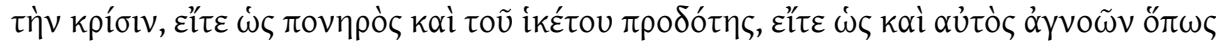

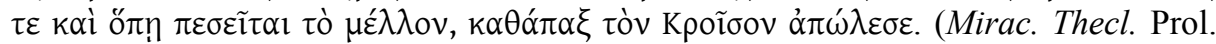
23-28 y $50-54)$
}

Tras este testimonio de los Milagros de Tecla se continuó transmitiendo el celebé-

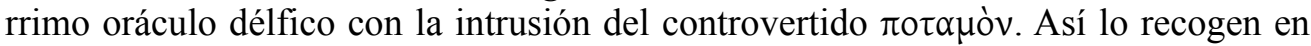
sus escritos al inicio de la literatura bizantina Juan Malalas (Chron. 155), y algo más tarde, en el siglo IX, Jorge el Monje en su Crónica (XIX 16). También aparece en el léxico Suda (K 2500), en la entrada dedicada al histórico rey lidio, aunque en esta ocasión encontramos otra nueva vuelta de tuerca y es que algún despistado copista alteró 
una vez más la estructura original que recogía Aristóteles e incluso la versión alterada

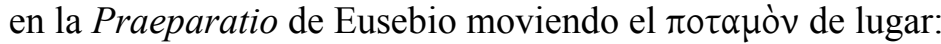

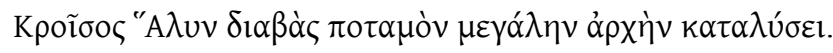

Por otro lado, paralelamente observamos también cómo el oráculo continúa circulando entre los escritores bizantinos tomado directamente de la obra de Aristóteles como demuestra el Pseudo-Nono en sus Escolios mitológicos (IV 95, 6), el autor anónimo del tratado Sobre la ciencia política $(42,16)$, Elías el filósofo en su Comentario sobre las categorías de Aristóteles $(126,38)$ y siglos más tarde Constantino VII Porfirogéneto en su De sententiis (290).

Mención aparte merece la $S u d a$, en la que en la entrada dedicada al término $\Lambda$ oł́́as ( $\Lambda$ 673) se incluye este famoso oráculo respetando - en este caso sí- el formato que poseía en el texto aristotélico y mostrando claramente con la aparición de las dos variantes de la misma respuesta oracular la doble transmisión que pretendíamos destacar.

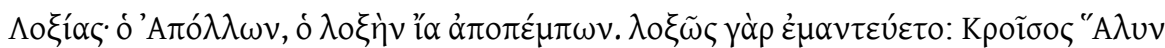

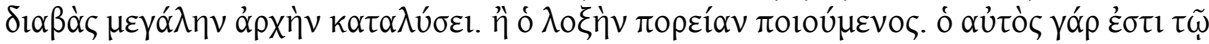

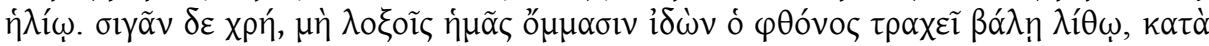

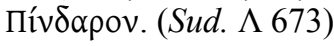

En definitiva, a través de este breve repaso por los textos que se hacen eco de la respuesta oracular que el dios Apolo ofreció al rey lidio Creso hemos podido comprobar cómo el hexámetro que Aristóteles recoge en su Retórica se transmite sin problemas hasta Eusebio de Cesarea. A partir de aquí y debido a un añadido de época temprana, seguramente una pequeña explicación, podemos encontrar una doble transmisión del

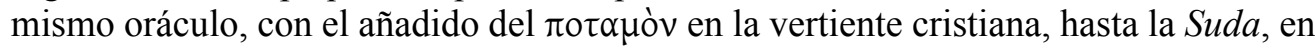
la que convivirán ambas tradiciones: una, la más clasicista inspirada en Aristóteles y la otra, la cristiana, que toma a Eusebio de Cesarea como texto de referencia.

\section{BIBLIOGRAFÍA}

Asheri, David (2011), «Book I» en D. Asheri, A. Lloyd \& A. Corcella (eds.), A Commentary on Herodotus. Books I-IV, Oxford: 57-218.

Caballero López, Antonio (2006), Inicios y desarrollo de la historiografía griega. Madrid.

CARgill, Jack (1977), «The Nabonidus chronicle and the fall of Lydia: Consensus with feet of clay», AJAH 2: 97-116.

CRAHAY, Roland (1956), La littérature oraculaire chez Hérodote. París.

Dagron. Gilbert (1974), «L'auteur des Actes et des Miracles de Sainte Thècle», AB 92: 5-11.

Dagron, Gilbert (1978), La vie et les miracles de Sainte Thècle. Bruselas.

Diels, Hermann A. (1903), Die Fragmente der Vorsokratiker. Berlín.

Fontenrose, Joseph (1978), The Delphic Oracle. Its Responses and Operations with a Catalogue of Responses. Berkeley, London \& Los Angeles. 
Hammerstadt, Jürgen (1988), Die Orakelkritik des Kynikers Oenomaus. Frankfürt.

HART, John (1983), Herodotus and Greek History. Manuka.

How, Walter W. \& Wells, Joseph (1928), A Commentary on Herodotus, Oxford.

Johnson, Aaron P. (2006), «Eusebius' Praeparatio Evangelica as Literary Experiment», en S.F. Johnson (ed.), Greek Literature in Late Antiquity. Dynamism, Didacticism, Classicism, Aldershot: 67-90.

López Salvá, Mercedes (1972), «Los Thaumata de Basilio de Seleucia», CFC 3: 217-319.

Manas, John H. (2004), Divination Ancient and Modern: An Historical, Archaeological and Philosophical Approach to Seership and Christian Religion. Whitefish.

Mikalson, Jon D. (2002), «Religion in Herodotus», en I. Bakker; I. J. F. de Jong \& H. Van Wees (eds.), Brill's Companion to Herodotus, Leiden, Boston \& Colonia: 187-198.

Mras, Karl (1954), Eusebius Werke 8-1. Berlin.

NARro, Ángel (2010), «Lo scontro tra formazione classica e pensiero cristiano: la Vita e Miracoli di Santa Tecla», Graeco-Latina Brunensia 15-2, pp. 127-138.

Nieto IbáÑez, Jesús María (1989), «Estudio estadístico del hexámetro de los oráculos de Delfos», RISSH 26, pp. 139-155.

Nieto IbÁÑez, Jesús María (1998), «Fórmulas homéricas y lenguaje oracular», Minerva 2, pp. 33-46.

Nieto IBÁÑEz, Jesús María (2011), Cristianismo y profecías de Apolo. Los oráculos paganos en la Patrística girega (siglos II-IV). Madrid.

Piñero, Antonio \& Del Cerro, Gonzalo (2006), Hechos Apócrifos de los Apóstoles II. Hechos de Pablo y Hechos de Tomás. Madrid.

Ross, William D. (1959), Aristotelis. Ars Rhetorica. Oxford.

Rossi, Luigi Enrico (1981), «Gli oracoli comme documento d'improvvisazione», en C. Brillante, M. Cantilena \& C.O. Pavese (eds.), I Poemi epici rapsodici non-omerici e la tradizione orale, Padova: 203-230.

Vallette, Paul (1908), De Oenomao Cynico. París.

West, Martin L. (1982), Greek Metre. Oxford. 